\title{
3 Research Square

\section{Evaluation Of Motor Performance In Cognitively Impaired Elderly Patients With Berg Test: A pilot study}

\section{Annamaija Sutela}

Malmin sairaala, City of Helsinki

Timo Kauppila ( $\square$ timo.kauppila@fimnet.fi )

Helsingin Yliopisto https://orcid.org/0000-0002-6155-0300

\section{Research note}

Keywords: Berg-test, dementia, elderly, motor performance, physiotherapy

Posted Date: May 19th, 2020

DOl: https://doi.org/10.21203/rs.3.rs-25673/v1

License: (c) (i) This work is licensed under a Creative Commons Attribution 4.0 International License.

Read Full License 


\section{Abstract}

\section{Objectives}

We studied whether we can determine a degree of cognitive impairment in which the testing for need of physiotherapy cannot be evaluated without continuous non-verbal instructions in the elderly patients.

Present study was a retrospective observational quasi-experimental cohort study performed with patients

of geriatric primary care hospital. Fifty-seven aged (>65 years) patients who are aiming to be rehabilitated to home-like facilities participated this study. We compared groups of different levels of cognitive performance (normal cognition, mild, moderate, and severe cognitive impairment) as determined with MiniMental(MMSE)-test by using their motor performance in Berg test.

\section{Results}

Severely cognitively impaired patients (MMSE $\leq 11$ ) were equally able to perform the Berg test as their less cognitively compromised controls if they were continuously advised non-verbally. However, standing without support, sitting without support, reaching forward, watching backwards by turning as well as turning around $360^{\circ}$ were too difficult tasks for these patients to be performed without continuous extra assistance given by the physiotherapists.

Even the most cognitively impaired patients may be able to perform a motor program in physiotherapy. However, with these patients autonomous exercise is likely to fail and excessive work by physiotherapists is thereby required for their training.

\section{Introduction}

Physiotherapy and related exercise is frequently required when elderly patients are rehabilitated after various clinical conditions affecting motor performance $[1,2,3]$. To compromise rehabilitation, many of the patients who have difficulties in, for example, obeying limitations of weight bearing after surgical reconstruction of a hip fracture are cognitively compromised and fail to remember movement limitations advised by the physiotherapist [2].

In our geriatric department, we had to focus our limited resources of physiotherapists on the training of those patients who might benefit the most. We had, however, limited knowledge about methods assessing ability to follow instructions and a motor program, their correlation to cognitive status and, thereby, about methods to select patients suitable for autonomous physiotherapy. Only reports we found $[4,5]$ suggested that the Berg test which thus is an instructed motor program [6] could be useful for this purpose. However, patients with severe cognitive impairment (Mini mental test score, MMSE > 10) were excluded from these experiments [5]. Berg test consists of 14 balance tasks common in everyday life and it is one of the most widely used methods for studying balance in the elderly [7]. 
Littbrandt et al. [4, 5] also used the MMSE-test to detect the degree of cognitive impairment. The MMSE test is highly used clinical method to assess the degree of dementia [8, 9]. Despite of its' inaccuracy to detect mild forms of dementia it is still the main method to detect dementia in the most clinical settings [9].

These tests, e.g. MMSE [8] and Berg test [6] had already been in clinical use in our department, too. Furthermore, it was reported that Berg test was performed only in patients with higher MMSE-score than 10 or more and we wanted to re-evaluate this finding [5]. Simultaneously, we attempted to study if there is a limit in the severity of cognitive impairment at which the patient is able to follow the simplest verbal instructions to perform motor tasks during assessment for physiotherapeutic training.

\section{Methods}

This study is a retrospective observational cohort study. Quasi-experimental setting [10] using convenient sample method [11] was used to obtain this patient cohort. Patients were selected from geriatric in- and out-patients of Katriina Geriatric Primary Health Care Hospital (City of Vantaa, Finland). Both local Ethics Committees [HUS Dnro 546/E9/01 and Vantaa City Dnro 27/2002) approved the study and the data were collected from the clinical files of those elderly patients (age > 65) who had already undergone MMSEand Berg-tests as part of their normal clinical physiotherapeutic rehabilitation route introduced due to various clinical problems.

\section{Primary outcomes}

In our institution, both MMSE and Berg test belong to the testing pattern of those patients who are aiming to be rehabilitated to home-like facilities. Altogether fifty-seven patients were tested. They were patients who were aiming to be rehabilitated to home-like facilities.

Patients were sent from the wards to the department of physiotherapy for evaluation of their balance in the rehabilitation process. In the beginning of their rehabilitation process the nurses of the wards performed MMSE tests. In the department of physiotherapy, six different therapists performed the Berg tests and the patients were sent back to their ward after this evaluation. Later on, the physiotherapists took part in making the rehabilitation plan for these tested subjects with the staff of the wards and performed physiotherapeutic training when necessary.

\section{Scoring and statistical analysis}

For the analysis, the patients had been divided into groups according to their MMSE score [8]. Patients with MMSE scores of 25 or higher were considered as a control group with normal cognition. Those patients whose MMSE score range was from 18 to 24 were considered as mildly cognitively impaired while those whose MMSE score range was from 12 to 17 were considered to be moderately cognitively impaired. If the MMSE score was 11 or less the patient belonged to the group of severely cognitively impaired patients. MMSE scores were obtained by specially trained nurses of the departments sending 
the patients to the physiotherapists. The MMSE-scores were not revealed to the physiotherapists. The Berg balance test [6] was performed and scored by physiotherapists. Maximum score was 56 points. In the original Berg-test the patient should have been able to perform the test tasks following a verbal advice which was allowed to be repeated once.

Unlike in the original test, our physiotherapists attempted to reach the best possible motor performance from the patient and when doing so they gave also non-verbal instructions to the patients if the patients were not able to perform the tasks solely with verbal advices. This meant that they showed the requested movements by giving visual examples. They marked this extra help on the test forms. This was due to an old local institutional instruction which had led to this variation of the test. Later on, the researcher scored as zero all those tasks where the physiotherapist had marked a sign of non-verbal instructions given in the testing form. This researchers' retrospective method of scoring is considered to be the appropriate way to perform and score the Berg test [6]. The patients were also divided into four groups according to their MMSE scores [8] and the two different Berg-test scoring methods were compared within these groups. The non-parametric analysis of variance (ANOVA, Kruskall-Wallis) followed by a post hoc evaluation (Dunn's test) was applied for analysis.

\section{Results}

Of the tested patients, twenty were considered as controls with normal cognition, twenty as mildly cognitively impaired, ten as moderately cognitively impaired and seven as severely cognitively impaired patients. The Berg test scores did not vary significantly between these four different groups derived by the state of the cognitive impairment (normal-mild-moderate-severe) if the extra non-verbal instructions given by the physiotherapists were ignored (Fig. 1a). However, all patients having these notes of needing nonverbal instructions had MMSE score 11 or less. When these signs were taken into account in scoring this group had lower scores in the Berg test than the other three groups (Kruskall-Wallis: $H=15,862, D f=4, P=$ 0,003 , Fig. 1a). Age of the patients did not explain the difference between these four groups with different cognitive status (ANOVA: $P=0.255$ ). The clinical conditions of our strongly cognitively compromised patients (MMSE 7-11) who were not able to perform the Berg test without non-verbal instructions are described in Table 1.

In five test tasks, the Berg test scores of the groups differed from each other. Also, cognitively normal patients had some problem to perform the Berg test as the testing proceeded. According to scores, the last four tasks seemed to be more difficult perform than the first ten tasks also in the cognitively normal group (Fig. 1b, $H=119,247, D f=13, P<0,001$ ).

Although, in standing without support (task $2,=15,787, \mathrm{Df}=4, \mathrm{P}=0,003$ ) and sitting without support (task $3, \mathrm{H}=14,984, \mathrm{Df}=4, \mathrm{P}=0,005)$ ANOVA revealed a significant variation between the groups none of the different groups of compromised cognition differed significantly from the cognitively normal patients in post hoc testing. In reaching forward (task eight, Fig. 2a., $H=16,927, \mathrm{Df}=4, \mathrm{P}=0,002$ ), watching backwards by turning (task ten, Fig. $2 \mathrm{~b}, \mathrm{H}=15,110, \mathrm{Df}=4, \mathrm{P}=0,004$ ) and turning around $360^{\circ}$ (task eleven, 
Fig. 2c, $H=13,885 D f=4, P=0,008$ ) these severely cognitively impaired patients needed non-verbal help from physiotherapists to perform equally well as the cognitively normal controls. Despite this non-verbal help, the cognitively most compromised failed to perform tasks No. 8 (Fig. 2a) and No. 10 (Fig. 2b) as well as cognitively normal patients. In other tasks, there were no statistically significant changes between groups of different cognition.

\section{Discussion}

Our results suggest that there may be a group of relatively strongly cognitively compromised patients (MMSE $\leq 11$ ) who can perform easy motor tasks if continuous guidance and surveillance is provided for the patient. Even patients with MMSE scores between 7 and 11 had the motor facilities needed to perform physiotherapeutic training if the assistance was continuous and thereby sufficient. Our result is in line with the report of Littbrand et al. [5] who found no significant differences in association between applicability and cognitive function regarding attendance, intensity, and adverse events during physiotherapeutic training, when comparing participants with dementia (MMSE 10-17) with participants without dementia. There was no significant correlation to the MMSE score at that score range, either [5]. In this aspect, our findings are also in line with the results reported earlier: e.g., physiotherapy and related exercise may benefit even the highly cognitively compromised patients $[1,2,3,12]$. Therefore, we would not categorically deny access of all strongly demented patients to assessment for physiotherapy by claiming that the stage of their dementia automatically inhibits the therapy.

According to the present data, the patient should have a MMSE score above 11 if they are supposed to have an ability to follow instructions and a motor program and to perform physiotherapeutic exercise programme autonomously. Thus, if structurally self-directed training is supposed to be fundamental for the rehabilitation, the strongly cognitively compromised patients are not the best candidates. Our data suggest that patients with moderate cognitive impairment, e.g. MMSE 12-17 [8,9] are still able to perform the Berg test when verbal instructions are provided. Indirectly, this finding is also in line with a former study in which those patients who were moderately demented (MMSE 11-17) were reported to benefit from physiotherapeutic rehabilitation after a hip fracture while those whose MMSE was 10 or below did not get that benefit [2].

There seemed to be certain tasks which were more difficult for strongly cognitively compromised patients to perform compared to the patients with normal cognition. This phenomenon has not been described before. Further studies are needed to determine if the ability of the patients to perform specific motor tasks differs depending on the severity of cognitive impairment. However, another putative explanation for this phenomenon could be speculated on the basis of the data of Fig. 1b. In cognitively normal patients, the scores of the tasks seem to decrease the higher the rank of the task in the performance sequence is. This suggests that the longer the Berg-test lasts the more strenuous the testing session gets both mentally and physically. The last part of the testing may be physically (and possibly also mentally) difficult and therefore even cognitively normal patients start to make so many mistakes that the level of performance between different groups of cognition fails to differ. Respectively, the attention needed to 
perform the test may decrease earlier in the cognitively strongly compromised patients than in patients with normal cognition: e.g. during tasks 8-11 the performance of the cognitively compromised patients starts to decrease more strongly than in the controls. This decrease in performance could be observed if we do not assist these patients with non-verbal instructions. Yet, the present results are in line with a hypothesis that relatively strongly cognitively impaired patients may be able to perform complex motor tasks if the guidance and surveillance of the patient is continuous. However, the patients should have a MMSE score above 11 before they may even have ability to perform pre-planned physiotherapeutic training programme alone. Physiotherapy in these patients (MMSE $\leq 11)$ may naturally turn out to be costly because excessive surveillance and unusual techniques may be required for their training [13].

\section{Limitations}

Our retrospective study was performed by using relatively crude methodology and had a small number of patients representing a convenient sample, which may reduce generalizability of the results [10]. For example, the patients in the group MMSE $\leq 11$ were thereby selected in a way that the departments attempted to rehabilitate them fit for home-like facilities and therefore they did not necessarily represent the majority of the strongly cognitively compromised patients in our hospital but rather represented a convenient sample [11]. Therefore, we had no patients below MMSE score 7 in this group, either. Furthermore, it is impossible to run this type of test so that physiotherapist running the Berg test would not recognize the worst levels of cognitive impairment. This, combined with the fact that these patients we planned to be discharged, may have enhanced the attempts to perform the Berg test even with those who had the lowest MMSE scores.

\section{List Of Abbreviations}

ANOVA analysis of variance

MMSE MiniMental-test

\section{Declarations}

\section{Acknowledgements}

We wish to thank city of Vantaa for continuous support to perform this study. We also wish to express our thanks to professors Lauri Niinistö and Jukka T. Salonen for their critical revision of our manuscript. We thank Tiia Ikonen, physiotherapist, Katriina Geriatric Primary Health Care Hospital, Vantaa, Finland, for collecting the data sheets.

\section{Consent for publication}

Not Applicable

\section{Competing interests}


Not applicable

\section{Data availability}

The datasets generated and analysed during the current study are not publicly available due to intimacy of the patients but are available from the corresponding author on reasonable request.

\section{Funding}

None.

\section{Ethics declarations}

\section{Ethics approval and consent to participate}

Both local Ethics Committees (HUS Dnro 546/E9/01 and Vantaa City Dnro 27/2002) approved the study. According to ethical boards, consent was not applicable here because the data were retrogradely collected from the clinical files of those elderly patients (age > 65) who had already undergone MMSEand Berg-tests as part of their normal clinical physiotherapeutic rehabilitation without researchers meeting the patients.

\section{Contributions}

Study concept and design: TK. Data collection and carried out the research: AMS. Qualitative analysis and interpretation of data: TK and AMS. First draft of manuscript: TK and AMS. Critical revision of the manuscript for important intellectual content and interpretation: TK and AMS. Review and approval of the manuscript: TK and AMS. All authors read and approved the final manuscript.

\section{References}

1. Tomlinson CL, Patel S, Meek C, et al. Physiotherapy versus placebo or no intervention in Parkinson's disease. Cochrane Datab Syst Rev. 2013;9:CD002817.

2. Huusko TM. Karppi P, Avikainen V, et al. Randomised, clinically controlled trial of intensive geriatric rehabilitation in patients with hip fracture: subgroup analysis of patients with dementia. BMJ. 2000;321:1107-11.

3. Forbes D, Forbes SC, Blake CM et al. Exercise programs for people with dementia. Cochrane Datab Syst Rev. 2015;4:CD006489.

4. Littbrand $\mathrm{H}$. Rosendahl $\mathrm{E}$, Lindelöf $\mathrm{N}$, et al. A high-intensity functional weight-bearing exercise program for older people dependent in activities of daily living and living in residential care facilities: Evaluation of the applicability with focus on cognitive function. Phys Ther. 2006;86:489-98.

5. Littbrand $\mathrm{H}$, Carlsson $\mathrm{M}$, Lundin-Olsson $\mathrm{L}$, et al. Effect of a high-intensity functional exercise program on functional balance: preplanned subgroup analyses of a randomized controlled trial in residential care facilities. JAGS 2011;59:1274-82. 
6. Berg KO, Maki BE, Williams JI, et al. "Clinical and laboratory measures of postural balance in an elderly population. Arch Phys Med Rehab.1992;73:1073-80.

7. Lee J, Geller Al, Strasser DC. Analytical review: focus on fall screening assessments. PM\&R. 2013;7:609-21.

8. Folstein MF, Folstein SE, McHugh PR. Mini-Mental State, a practical method for grading the cognitive state of patients for the clinician. J Psychiatr Res. 1975;12:189-98.

9. Arevalo-Rodriguez I, Smailagic N, Roqué i Figuls M. et.al. Mini-Mental State Examination (MMSE) for the detection of Alzheimer's disease and other dementias in people with mild cognitive impairment (MCl). Cochrane Datab Syst Rev. 2015;3:CD010783.

10. Grimshaw J, Campbell M, Eccles M, et al. Experimental and quasi-experimental designs for evaluating guideline implementation strategies. Fam Pract. 2000;17(Suppl no. 1):11-6.

11. Karhula T, Kauppila T, Elonheimo O, et al. Use of e-mail in communication between Finnish health care system and general practitioners. Inform Prim Care. 2011;19:25-32.

12. Blankevoort GC, van Heuvelen MJ, Boersma F, et al. Review of effects of physical activity on strength, balance, mobility and ADL performance in elderly subjects with dementia. Dement Geriatr Cogn Disord. 2010:30:392-402.

13. Hall AJ, Lang IA, Endacott R, et al. Physiotherapy interventions for people with dementia and a hip fracture-a scoping review of the literature. Physiother. 2017;103:361-8.

\section{Table}


Table 1: Table 1. Causes of severe cognitive impairment and associated diseases (MMSE 7-11) who were not able to perform the Berg test without non-verbal instructions are described.

\begin{tabular}{|c|c|c|c|}
\hline $\begin{array}{l}\text { Age } \\
\text { (y) }\end{array}$ & $\begin{array}{l}\text { MMSE } \\
\text { score }\end{array}$ & $\begin{array}{l}\text { Disease causing } \\
\text { dementia }\end{array}$ & Associated diseases \\
\hline 80 & $7 / 30$ & $\begin{array}{l}\text { Alzheimer's } \\
\text { disease }\end{array}$ & \\
\hline 77 & $8 / 30$ & Unknown & \\
\hline 91 & $11 / 30$ & $\begin{array}{l}\text { Alzheimer's } \\
\text { disease }\end{array}$ & Arterial hypertension, renal cancer \\
\hline 81 & $9 / 30$ & $\begin{array}{l}\text { Vascular } \\
\text { dementia }\end{array}$ & Depression, status after cerebral contusion \\
\hline 87 & $8 / 30$ & $\begin{array}{l}\text { Vascular } \\
\text { dementia }\end{array}$ & Cerebral infarct, chronic subdural haemorrhage \\
\hline 79 & $8 / 30$ & $\begin{array}{l}\text { Alzheimer's } \\
\text { disease }\end{array}$ & Arterial hypertension \\
\hline 91 & $11 / 30$ & $\begin{array}{l}\text { Alzheimer's } \\
\text { disease and } \\
\text { vascular } \\
\text { dementia }\end{array}$ & $\begin{array}{l}\text { Arterial hypertension, coronary disease, asthma, status } \\
\text { post subdural haemorrhage }\end{array}$ \\
\hline
\end{tabular}

\section{Figures}


A

\section{Effect of cognitive status on total Berg-test scores}

* $\mathrm{P}<0.05$, Dunn's test (compared with normals)

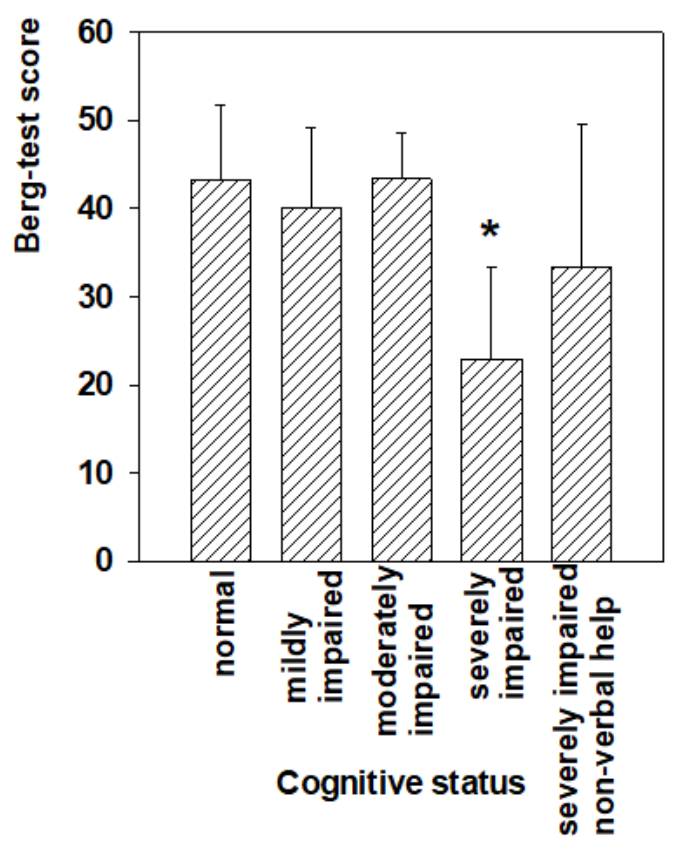

B

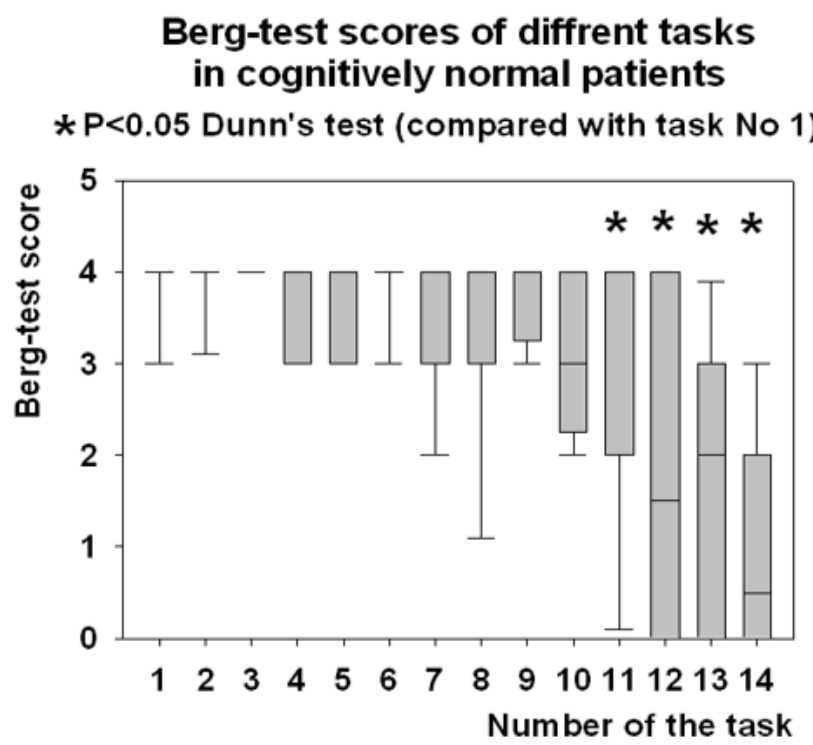

\section{Figure 1}

Comparison of the total Berg test scores between the patients in different categories of cognitive impairment. Mean $\pm \mathrm{SD}$ is shown (Figure $1 \mathrm{~A}$ ). Comparison of the Berg test scores between the tasks in patients with normal cognition. Median (line in the bar) ,25, $75 \%$ (margins of the bars), 10 and 90\% (brackets) and maximum or minimum (dots) are shown (Figure 1B).

A

Effect of cognitive status on Berg-test on task eleven

* $\mathrm{P}<0.05$, Dunn's test (compared with controls)

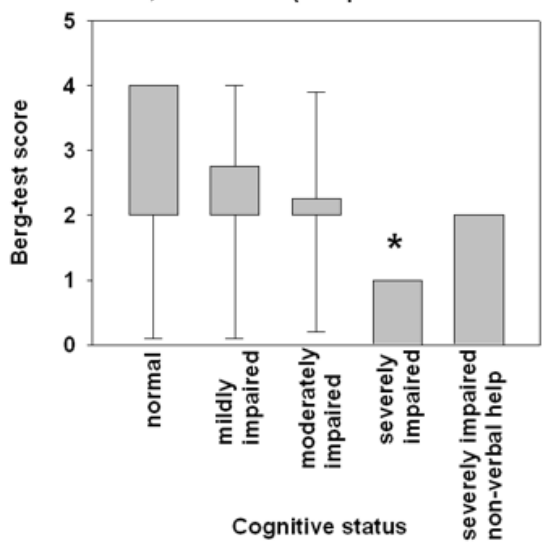

B

Effect of cognitive status on Berg-test scores in task eight

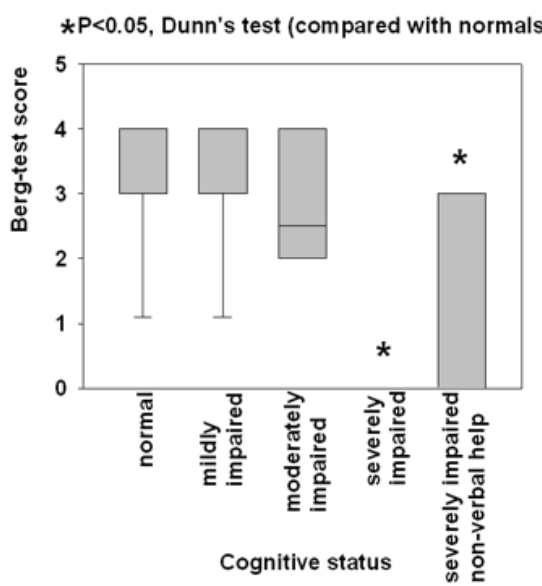

C

Effect of cognitive status on Berg-test scores in task ten

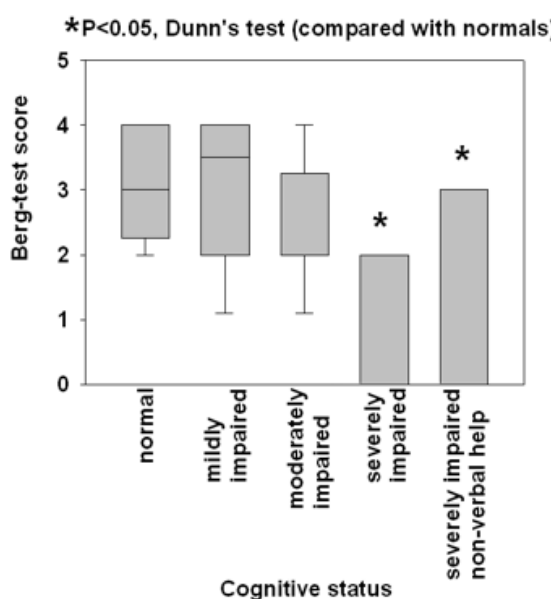

Figure 2 
Comparison of the Berg test scores between the patients in different categories of cognitive impairment in 8 (reaching forward, Figure 2A), in task 10 (watching backwards by turning, Figure 2B) and in task 11 (turning around $360^{\circ}$, Figure 2C). Median (line in the bar) ,25, $75 \%$ (margins of the bars), 10 and $90 \%$ (brackets) and maximum or minimum (dots) are shown. 